\title{
ИТОГИ ВЫСТАВКИ «МЕТАЛЛООБРАБОТКА-2019" В КОНТЕКСТЕ ГОСУДАРСТВЕННОЙ ПОЛИТИКИ ЦИФРОВИЗАЦИИ ЭКОНОМИКИ
}

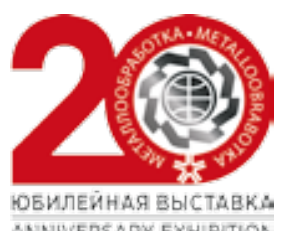

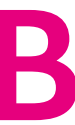

ыставка "Металлообработка-2019" закончила свою работу. 20-я международная специализированная выставка "Оборудование, приборы и инструменты для металлообрабатывающей промышленности" проходила в Москве в ЦВК "Экспоцентр" с 27 по 31 мая 2019 года. "Металлообработка" традиционно охватывает практически все аспекты машиностроения, металлообработки, станкостроения. Чем же "Металлообработка-2019" отличался от мероприятий подобного уровня прошлых лет?. В этом году в экспозиции появились новые разделы: "Сварка и родственные технологии" и "Робототехника и автоматизация производства". Получил развитие раздел "Аддитивные технологии. Промышленная 3D печать". Организаторы выставки уделили пристальное внимание аддитивным технологиям, которые являются неотъемлемым компонентом реализации концепции "Индустрия 4.0". Это одно из самых перспективных направ- лений для инновационного развития отечественного производства. Несколько цифр, представленных пресс-службой выставки, показывают ее размах:

- 1186 компаний-участников из 33 стран мира;

- в том числе 544 российских компаний;

- 9 национальных и коллективных экспозиций: Республика Беларусь, Великобритания, Германия, Италия, Китай, Словакия, Тайвань, Чешская Республика, Швейцария;

- 42385 кв. м. площадь выставки (рост +3\% по сравнению с 2018 годом);

- 35096 посетителей-специалистов (рост $+8 \%$ по сравнению с 2018 годом).

Партнером "Экспоцентра" по организации выступила Российская Ассоциация производителей станкоинструментальной продукции "Станкоинструмент", патронаж обеспечила Торгово-промышленная палата РФ, поддержку оказали Совет Федерации Федерального Собрания РФ,
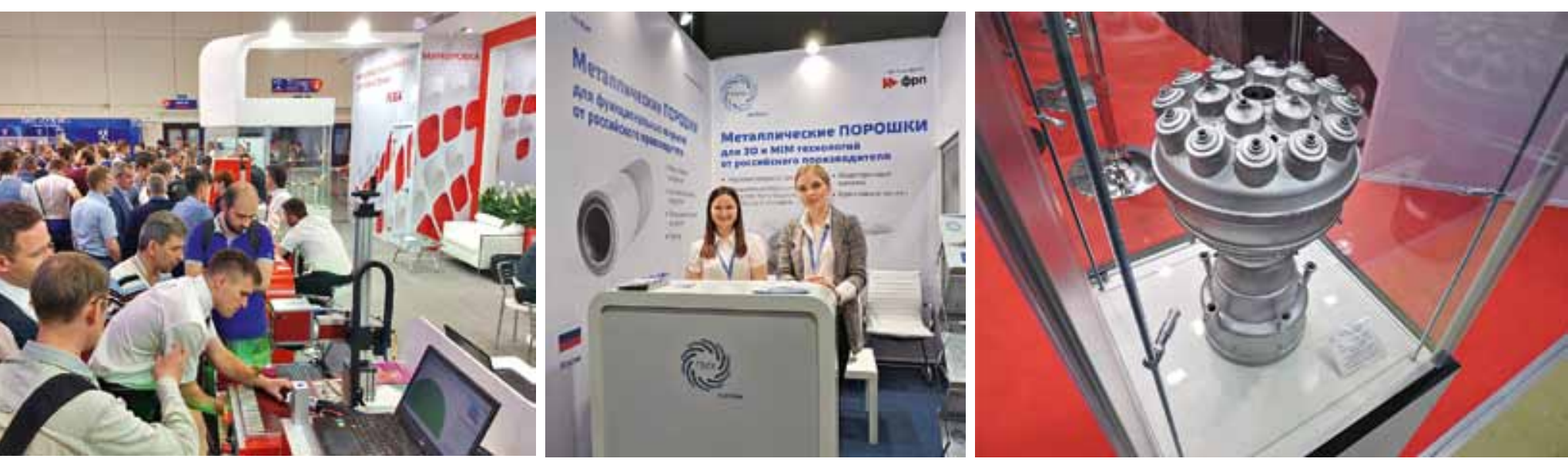
Министерство промышленности и торговли РФ, Союза машиностроителей России. Высокий уровень иностранного участия и посетителей свидетельствует о большом интересе зарубежных фирм к ведущей отраслевой выставке и российскому рынку машиностроительной продукции (визиты чрезвычайного и полномочного посла Республики Индия в РФ Д.Б. Венкатешу Варме и посла Швейцарии в России г-на Ив Россье, участие генерального секретаря Ассоциации производителей станкоинструментального оборудования Швейцарии (SWISSMEM), члена правления немецкой Ассоциации станкостроителей (VDW), президента Ассоциации производителей оборудования и инструмента Китая (СМТВА), генерального директора БЕЛОРГсТАНКИНПРОМ (Республика Беларусь), заместителя генерального секретаря турецкой Ассоциации производителей станков (MIB), заместителя генерального секретаря Ассоциации предпринимателей и производителей станков (TIAD, Турция), исполнительного генерального секретаря Ассоциации станкостроителей Тайваня (ТМВА), а также представителей Ассоциации машиностроительных технологий Чешской Республики (SST), Ассоциации итальянских производителей станков, роботов, средств автоматизации и вспомогательной продукции (UCIMU), Ассоциации производственных технологий Великобритании (МТА), Тайваньской Ассоциации машиностроительной индустрии (ТАMI), Ассоциации производственных технологий США (АМТ), Ассоциации станкостроителей Японии (JMTBA).

Зарубежные отраслевые ассоциации привезли на выставку коллективные экспозиции. С использованием VR-технологий Совет по внешнеторговому развитию Тайваня (TAITRA) пред-

\section{Лннзы}

для промышленных лазеров

Дании Сафонов, заместитель директора по коммерции, и Киримл Чупахин, руководитель по развитию направления оптики дпя технопогических пазеров группы компаний R'AIN

Компания «НН ОПТИКА» представила на выставке фокусирующие линзы для промышленных лазеров, полный цикл серийного изготовления которых выполнен в России впервые. Мощные технологические $\mathrm{CO}_{2}$-лазеры с излучением на длине волны 10,6 мкм широко используются в области промышленной обработки материалов. Для изготовления фокусирующей и проходной оптики в системах $\mathrm{CO}_{2}$-лазеров высокой мощности (от 2 кВт) используют оптику, изготовленную только из селенида цинка лазерного качества. Это обусловлено высокой лучевой стойкостью материала и низким поглощением на длине волны 10,6 мкм. Лазерная оптика технологических лазеров является расходным материалом. В лазерах мощно-

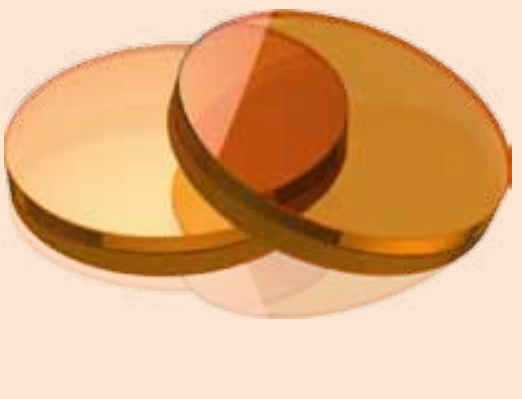

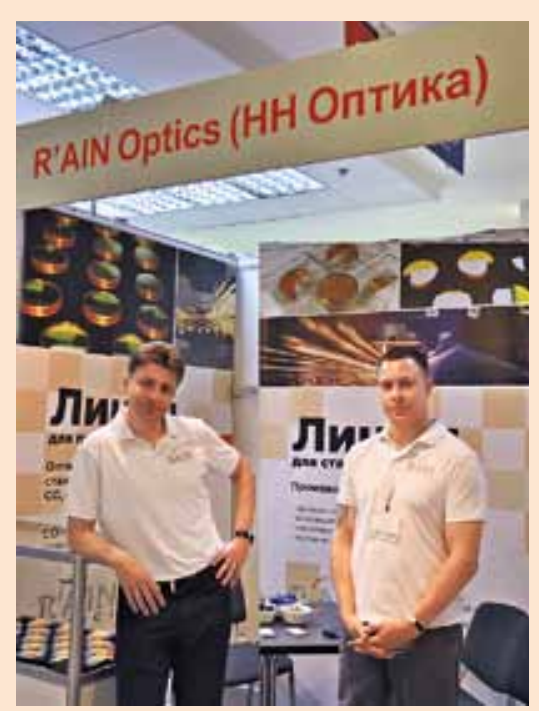

стью от 2 до 5 кВт срок службы линз составляет в среднем 3-6 недель, время наработки остальных оптических элементов составляет около 1500 час. Поэтому рынок оптических материалов и деталей из них для технологических лазерных установок постоянно растет во всем мире, в том числе и в России.

Компания "НН ОПТИКА» является лидером на российском рынке производителей селенида цинка лазерного качества. Компания обладает самым современным оборудованием по выращиванию материала, его обработки и нанесение оптических покрытий для фокусирующей оптики. Покрытие линз для промышленных лазерных установок R'AIN Optics не содержат радиоактивных материалов.

www.r-ainoptics.com ставил новейшее оборудование и современные технологии от крупнейших производителей в рамках стратегии "Индустрия 4.0" на примере таких компаний как AccuteX, YCM, Soco, TTGroup, YLM (Hannsa), Kova, SEYI, Hiwin, Techman Robots, Apec. Использование виртуальной реальности стало уже визитной карточкой тайваньского павильона. На конференции «Технологии будущего - сегодня" зрители по-настоящему погрузились в виртуальную вселенную: совершили путешествие на заводы Тайваня и даже собрали виртуальную линию 
производства с помощью интерактивного элементов, интегрированных в виртуальный опыт. Интересно, что. программа "Интеллектуальное машин ное оборудование» соответствует одной из пяти целей промышленного развития, поставленных президентом Тайваня Цай Инвэнь. В 2018 году Министерство экономики Тайваня (MOEA) запустило пятилетнюю программу по установке более 9000 интеллектуальных блоков станков (SMB), которые позволяют компаниям быстро добавлять к существую- щему оборудованию возможность подключения к Интернету вещей (IoT). Это делается для сбора данных о продукции, чтобы облегчить визуализацию управления производством и оптимизацию процесса планирования производства. За счет интеллектуализации машинного оборудования и устройств Министерство экономики намеревается повысить качество, эффективность, точность и надежность производств, тем самым повысив конкурентоспособность тайваньских компаний.

\section{Новая технология LaserBarking ${ }^{\circledR}$}

Сергей Горныци, генерапьный директор компании "Лазерный центр"

Выставочная экспозиция компании «Лазерный центр" включает большое количество разнообразных лазерных станков для различных технологических операций. Компания представила станки для лазерной маркировки и гравировки («МиниМаркер-2" и "Турбомаркер»), для лазерной сварки ("Фотон-компакт» и «Фотон-150») и прецизионной резки (RX-150) металлов и сплавов, специальные лазерные системы обработки материалов электронной техники («МикроСЕТ»), установки лазерноэрозионной обработки ("Турбоформа»). В установке "Турбоформа" реализована новейшая, не имеющая аналогов на российском рынке система трехмерной лазерной гравировки высочайшего качества. В этом году мы представили новую технологию лазерной 3D-гравировки - лазерно-эрозионную обработку материалов LaserBarking ${ }^{\circledR}$.

Технологию лазерно-эррозионной обработки с уверенностью можно назвать откры-
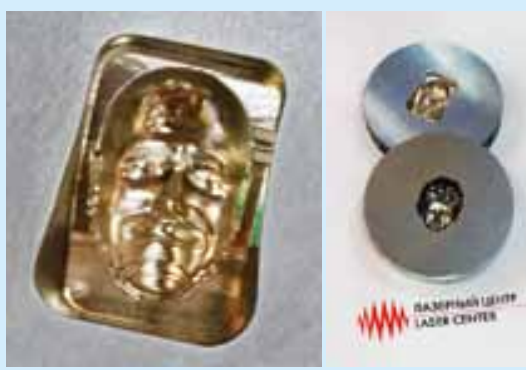

тием - в мире такого нет. Технология получила название Laser Barking. Barking в английском языке имеют много разных значений, и одно из них является "окоревание». Окорка - это процесс зачистки внешнего слоя стволовой части дерева (снятие коры), происходящий после того, как с него будут удалены ветви и сучья. Еще "to bark» переводится с английского языка как "собака лает по-собачьи". Аналогия того, что как будто собака выгрызает металл любой твердости с фантастическим качеством и на любую глубину. Технология лазерно-эрозионной обработки основана на механизме контролируемого удаления тонких слоев обрабатываемого материала в результате воздействия сфокусированного лазерного излучения, параметры которого варьируются по специально разработанному пО. Качество поверхности получается на уровне полировки материала или материала, прошедшего обработку на полировальном станке высокого класса.

Мы видим, что у технологии большой потенциал применения. Тем более технология позволяет очень быстро изготавливать пресс-форму. Обычными способами прессформа делается за 3-6 месяцев, а мы делаем за десятки часов. Часто задают вопрос; какая получается шероховатость. Дело в том, что после лазерной обработки трудно описать получаемую поверхность в терминах шлифовального станка, потому что поверхность сама по себе разная. После лазерной обработки поверхность имеет не только структуру, схо-

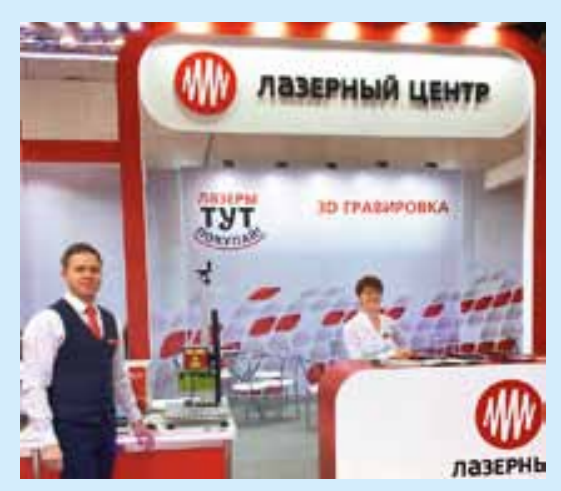

жую с той, что образуется после шлифовального инструмента, но еще и микрошероховатость за счет дополнительного оплавления.

Технология позволяет создавать заданные формы в материалах с очень высокой твердостью, например в штамповых сталях с твердостью по Роквеллу HRC = 58 единиц. Штамповые стали используются при изготовлении штампов и пуансонов сложных конфигураций, которые при закалке должны мало деформироваться. Соответственно технологию можно использовать в производстве пресс-форм для литья алюминия или иных других легкосплавных материалов. Уже получены пластмассовые детали высокого качества и высокой точности с помощью литья в формы, выполненные с помощью LaserBarking-технологии.

Мы внедрили LaserBarking-технологию полностью в оборудование (лазерная система "Турбоформа"), запатентовали ее в России, и в ближайшее время она пойдет по мадридской системе патентования по всему миру.

www.newlaser.ru 
На протяжении многих лет Тайвань остается одним из ключевых поставщиков станков на российском рынке. Например, в 2018 году объем импорта тайваньских станков и комплектующих достиг 141,289 миллионов долларов, что сделало Тайвань четвертым по величине поставщиком станков в России.

Удачную коллективную экспозицию представил Центр поддержки внешнеэкономической деятельности в сфере промышленности и АНО "Моспром", собрав вместе многие российские компании, производящие уникальную продукцию и станки на базе инновационных лазерных технологий. Много благодарных слов в адрес Московского экспортного центра прозвучало от экспонентов, выпускающих лазерные анализаторы и измерительные устройства, комплектующие, узлы и элементы для лазеров и лазерной техники, а также различные оптические элементы для волоконных лазеров и $\mathrm{Nd}$ : YAG-лазеров.

Для понимания практических целей, преследуемых организаторами выставки в контексте проводимой государством политики по цифровизации экономики, рассмотрим деловую программу, сопровождавшую выставку "Металлообработка-2019". Деловая программа включала в себя почти 30 отраслевых мероприятий, в которых приняли участие представители органов государственной власти, профильных министерств, крупного и малого бизнеса, ведущих отраслевых ассоциаций и научных центров, специалисты разного уровня.

Кажется, необходимость внедрения лазерных и фотонных технологий медленно и постепенно находит понимание у организаторов отрасли. 27 мая состоялся семинар "Новейшие лазерные технологии для обработки материалов" (организатором выступила компания "ООО "Лазерный Центр"). В программе семинара прозвучали доклады по теме лазерной маркировки и гравировки изделий, использовании волоконных лазеров производства компании "НТО ИРЭ-Полюс" и роботов компании FANUC, а также об использовании лазерных технологий в производстве микроэлектронных приборов (например, при тонкопленочной металлизации с операцией лазерного вскрытия, компания RMT). Во время семинара компания "Лазерный Центр" анонсировала свою новую запатентованную уникальную технологию лазерно-эррозионной обработки laser barkin для производства штамповой оснастки и пресс-форм. Параллельно с семинаром проходила конференция "Передовые решения для сварочного производства". В списке докладов также отметим выступление, связанное с лазерными технологиями: доклад К. Рожкова (компания FANUC PEНА СОЛЮШИНС) "Роботизация процессов MIG/MAG сварки". 28 мая прошла Международная конференция "Цифровое производство: ПО и оборудование для фабрики будущего", в ее рамках прозвучал доклад Е.Земля-
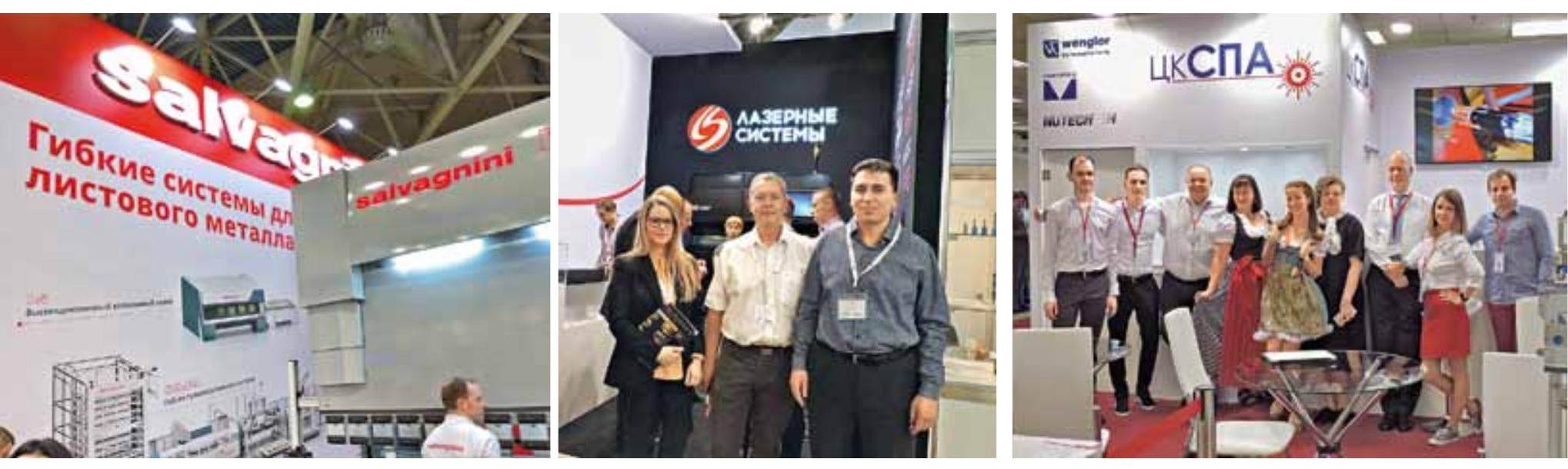
кова (ИлИСТ СПбГмТУ) «Прямое лазерное выращивание крупногабаритных деталей: технология и оборудование", а на секции № 3 "Сварка и родственные технологии в станкостроении" (9-й Международный научно-технический форум
«Технологии обработки материалов, робототехника и Индустрия 4.0") с докладом "Особенности технологии сварки волоконными лазерами IPG" выступил начальник отдела лазерной сварки и наплавки НТО "ИРЭ-Полюс" Н. В.Грезев. Но это очень маленькая доля в общем объеме рассматриваемых вопросов. Хотя отрасль фотоники обозначена Минпромторгом России как обслуживающая отрасль, принятые направления на достижение целей цифровизации не могут быть достигнуты без использования лазерных источников, формирующих оптических систем, оптоэлектронных приемников. Поэтому выставке не хватало акцента на отрасль фотоники. Этот недостаток заслуживает самого пристального внимания и обсуждения.

Ключевым мероприятием деловой программы стал 9-й Международный научнотехнический форум "Технологии обработки материалов, робототехника и Индустрия 4.0". Форум был открыт 28 мая пленарным заседанием "Развитие потенциала промышленности России. Вклад Российского стан ${ }^{-}$ костроения в реализацию национальных проектов".

Машиностроительный ком- $^{-}$ плекс - один из лидеров получения государственных субсидий. Директор департамента стан ${ }^{-}$ костроения и инвестиционного машиностроения Минпромторга России М.И. Иванов рассказал о перспективах участия предприятий станкостроения в реализации национальных проектов для достижения целей, определенных Указом Президента Российской Федерации № 204. В докладе он уделил особое внимание механизму корпоративных программ повышения конкурентоспособности (КППК), способствующему увеличению 
производства конкурентоспособной продукции (эти программы были приняты особым постановлением Правительства Российской Федерации), принципам отбора участников, реализующих КППК, и порядку заключения с ними соглашений о предоставлении субсидий в рамках банковского кредитования. Национальный проект "Международная кооперация и экспорт" направлен на поддержку компаний, реализующих корпоративные программы повышения конкурентоспособности (КППК). После запуска программы, с 2020 года, господдержку получат только те игроки, которые готовы взять на себя обязательства по экспорту. Принять участие в этой программе пожелали многие компании. Поэтому отбор получателей субсидии по 191-му постановлению был продлен до 15 июня 2019 года. В августе с победителями конкурса будут заключены соглашения. (Примечание: позже в интервью, данном 7 июня главой Минпромторга России корреспонденту ТАСС, было сказано, что не исключено, что к концу года будет проведен еще один этап конкурса). В бюджете 2019 года на расходы по программе КППК было заложено порядка 10 млрд рублей.

\section{Лазерная обработка в режиме job-shop}

Антон Шевела, руководитель отдела продаж компании «Лазерный регионапьный Северо-Западный центр - "Лазертех", Санкт-Петербург.

Компания "Лазерный региональный северозападный центр - "Лазертех», Санкт-Петербург, представила на выставке свои компетенции в сфере оказание услуг по лазерной обработке в режиме job-shop: лазерная резка, закалка, сварка, очистка, легирование, наплавка, маркировка. Компания, опираясь на свой более чем 30-летний опыт, продвигает на российском рынке инновационное лазерное оборудование других стран с высокими рабочими характеристиками. Среди них HGTесh - ведущая компания в китайской металлообрабатывающей отрасли, вторая в Китае по обороту продаж с прошлогодним результатом 780 млн долларов. Основанная в 1997 году, в 2000 году компания НСТесһ становится владельцем австралийской компании Farley Laserlab, производящей лазерные и плазменные установки с 1977 года. Соответственно HСТесh стала владельцем полностью всех технологий и мощностей. HСТесh имеет в своем составе научно-исследовательские центры и конструкторское бюро и представляет

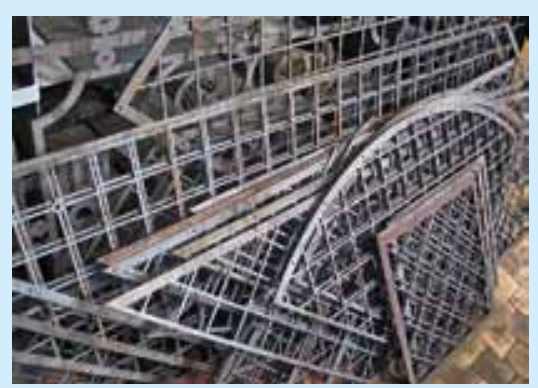

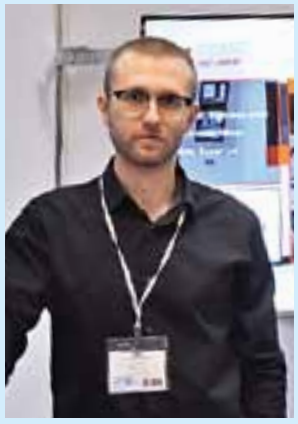

полную продуктовую линейку под разные технологические задачи: и для лазерной резки, и для сварки, термообработки, есть лазерные маркировщики, установки лазерной очистки.

В этих системах используются волоконные лазеры производства компаний IPC Photonics и Raycus. Волоконные лазеры компания IPC Photonics славятся своим качеством и высокой надежностью за счет высочайшего качества сборки. Raycus - китайская компания, основанная в 2007 году, в 2010 году излучатели марки Raycus были признаны достоянием нации. Волоконные лазеры Raycus аналогичны продукции компании IPC, их производство также обладает высокой надежностью (гарантия на лазерные источники до 5 лет). Все другие комплектующие станков также производятся мировыми лидерами: системы ЧПУ и сервоприводы производства Siemens, лазерные головки от компании Precitec, то есть все комплектующие лазерных станков самого высокого класса, но есть бюджетные решения, подходящие для российского рынка. Компания «Лазерный региональный северозападный центр - «Лазертех" является сертифицированным представителем компании HGTech.

www.laserteh.ru
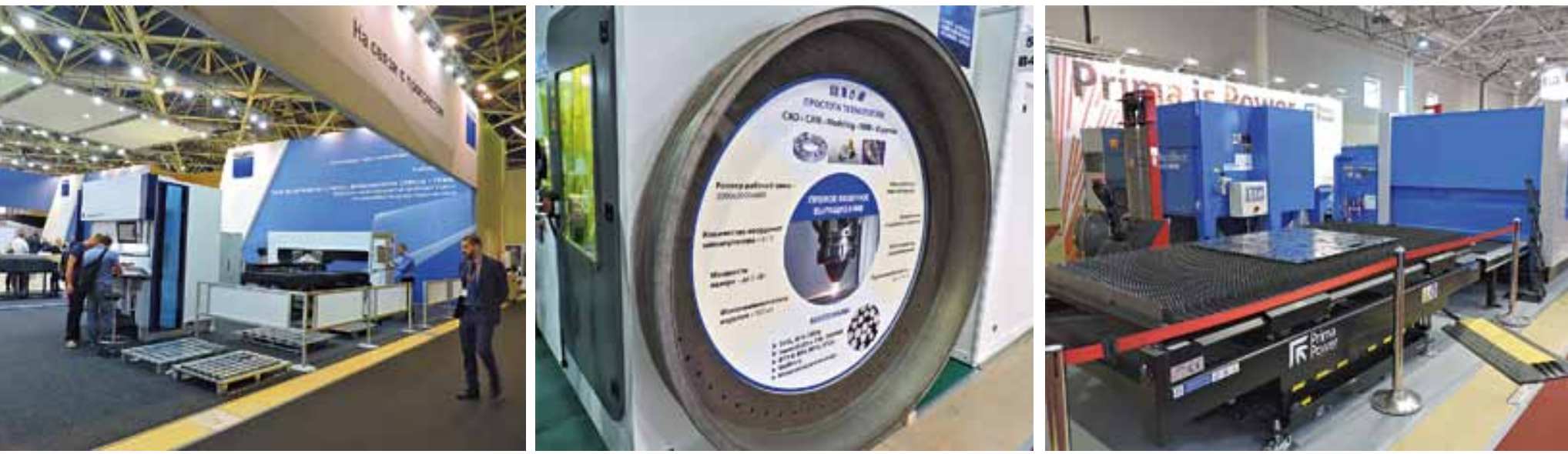

Photonics VOL. 13 № 42019 


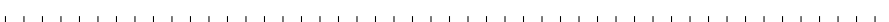

\section{Самое большое в мире кольцо авиадвигателя из титанового сплава}

Евгений Земяяков,

заместитель директора по научной и проектной деятепьности, Институт пазерных и сварочных технопогий СПбгмТу.

Экспозиция Института лазерных и сварочных технологий СПбГмТу на выставке "Металлообработка-2019" полностью обновлена по сравнению с 2018 годом. ИлИст представил на выставке новые, не имеющие аналогов в мире, инновационные разработки. В их числе - серийная установка прямого лазерного выращиванию с габаритами рабочей зоны $1300 \times 1300 \times 800$ мм.

Специальную презентацию оборудования, разработанного в ИлИСт СПбГмту для предприятий-партнеров, сделал ректор вуза Глеб Туричин. В числе слушателей данной презентации были представители предприятий, входящих в государственные корпорации ОСК, ОДК, КТРВ, «Высокоточные комплексы».

Также на стенде демонстрировались примеры изделий, полученных на установке прямого лазерного выращивания. Отдельное место на стенде ИлИСТ заняло самое большое в мире кольцо авиадвигателя из титанового сплава диаметром 2100 мм, полу-

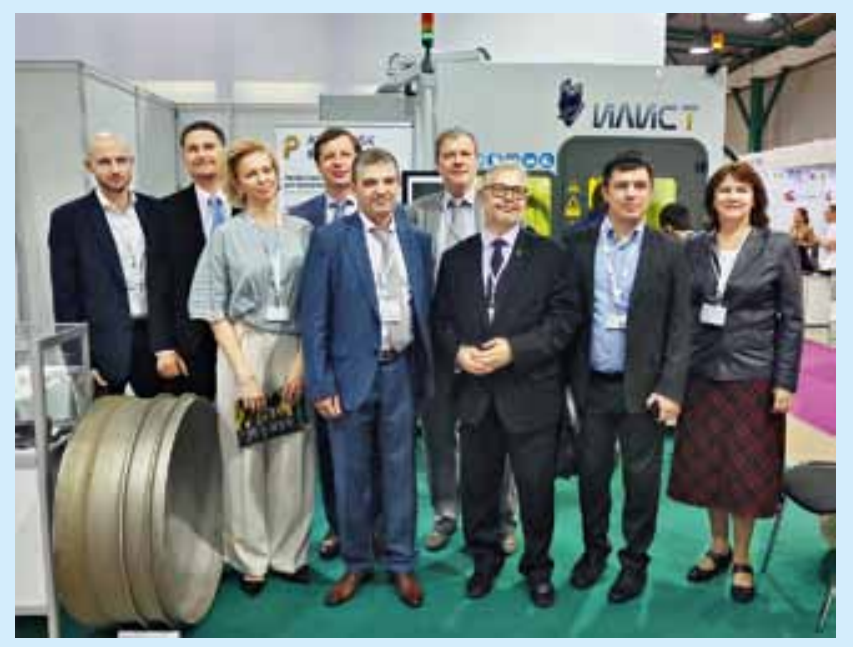

ченное методом прямого лазерного выращивания.

Участники и гости выставки могли воочию увидеть, что из себя представляет технология создания высокоточных заготовок изделий сложной формы из металлических порошков по заданным 3D-моделям. Каждый посетитель стенда мог наблюдать, как быстро строится изделие из порошка, подаваемого в зону воздействия лазерного луча и буквально растет на глазах.

Преимущества внедрения технологии прямого лазерного выращивания заключаются в значительном снижении производственной себестоимости изготовления металлических деталей за счет снижения временных затрат, повышения коэффициента использования материала, снижения затрат на последующую механическую обработку. При этом механические свойства выращенного материала не уступают металлопрокату и значительно превосходят свойства литья.

WWw.smtu.ru
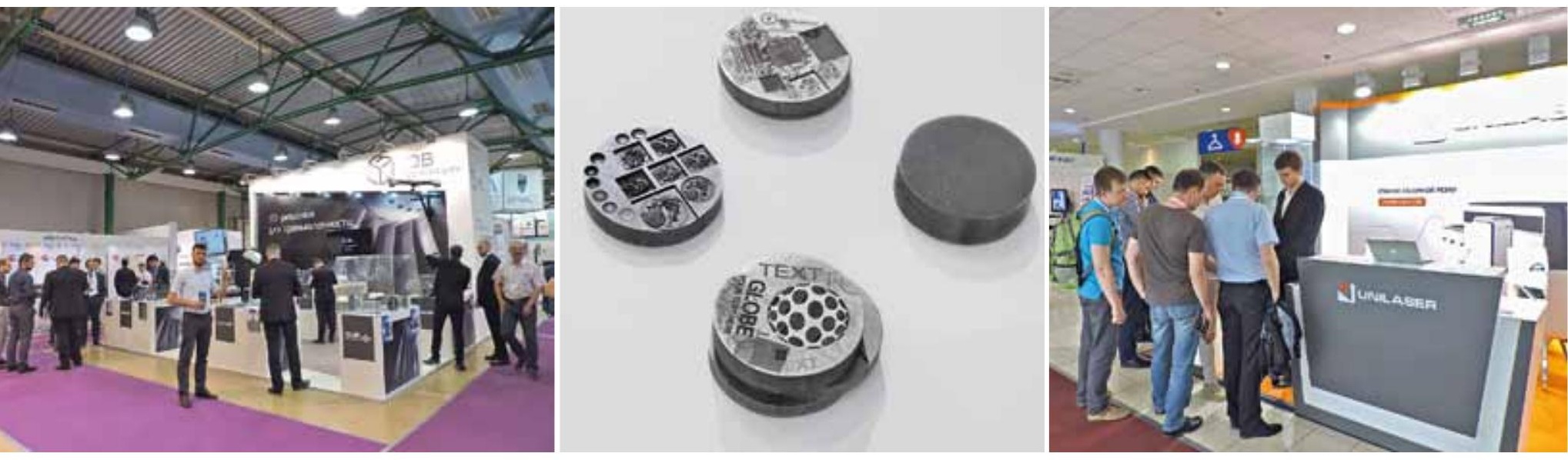
